\title{
Gastric cancer following highly selective vagotomy
}

\author{
P.W.J. Houghton and D.J. Leaper \\ University Department of Surgery, Bristol Royal Infirmary, Bristol BS2 8HW, UK.
}

\begin{abstract}
Summary: A case of gastric cancer occurring seven years after a highly selective vagotomy is described. This operation may not be the appropriate choice for the surgical treatment of gastric ulcers and $\mathrm{H}_{2}$ blockers should be used with caution in these patients.
\end{abstract}

\section{Introduction}

Cancer in the remnant following gastric resection for peptic ulcer disease is a well recognized clinical entity although its incidence remains controversial. ${ }^{1,2}$ Likewise, gastric cancer occurring after gastroenterostomy ${ }^{3}$ and vagotomy and pyloroplasty ${ }^{4}$ has also been described. In the last 10 years highly selective vagotomy (HSV) has become the operation of choice for many surgeons as the elective surgical treatment of peptic ulcer disease. We report a case of gastric cancer occurring 7 years after HSV, an association which has not been reported before.

\section{Case report}

A 48 year old man presented in March 1976 with a 6year history of dyspepsia. A barium meal showed a gastric ulcer on the lesser curve just above the incisura, a deformed duodenal cap, and delayed gastric emptying. In view of the length of history and failure of medical management he underwent a highly selective vagotomy, excision of the gastric ulcer and digital dilatation of the pylorus. Burge and Grassi tests indicated a complete vagotomy at the end of the procedure and a Hollander insulin test on the sixth postoperative day was negative. Histology of the gastric ulcer confirmed it to be benign.

The patient remained well until December 1980 when he returned to out-patients complaining of recurrent dyspeptic symptoms and a gastroscopy revealed an anterior, prepyloric ulcer. Gastric function tests showed a basal acid output of $0 \mathrm{mmol} / \mathrm{h}$, a peak acid output (insulin) of $0.34 \mathrm{mmol} / \mathrm{h}$ and a peak acid output (pentagastrin) of $19.98 \mathrm{mmol} / \mathrm{h}$. He was commenced on cimetidine but was lost to follow-up until March 1982 when he was re-referred after having been on cimetidine for one year with continual dyspeptic

Correspondence: D.J. Leaper, F.R.C.S.

Accepted: 31 July 1986 symptoms. A repeat gastroscopy again showed an active prepyloric channel ulcer. Multiple biopsies showed no evidence of malignancy but revealed an excessive degree of superficial hyperplasia for a benign ulcer and careful follow-up was recommended. Cytology was also negative and he was commenced on high dosage cimetidine. Over the next 6 months he had two further gastroscopies. Biopsies after the first showed severe gastritis, intestinal metaplasia, and severe dysplasia but the second biopsies showed that these changes were less pronounced.

In July 1983 he had a further endoscopy and this now revealed a hard irregular ulcerated area near the antrum which biopsy confirmed to be malignant. A distal half gastrectomy with a retrocolic gastrojejunostomy was performed with difficulty, the tumour being adherent to the pancreas and the liver to the lesser curve. Histology confirmed a moderately differentiated adenocarcinoma. His postoperative course was complicated by a pancreatic fistula and a pulmonary embolus. Four months after surgery he was readmitted with jaundice and evidence of widespread metastatic disease and he died shortly after.

\section{Discussion}

Risk factors associated with gastric carcinogenesis include achlorhydria and duodeno-gastric reflux. ${ }^{5}$ Since the latter is not increased after HSV, unlike other gastric operations ${ }^{6}$ theoretically the risk of developing surgically induced gastric cancer should be reduced. However, HSV, as well as producing achlorhydria, preserves the gastric antrum and gastric cancer is known to have a predilection for this site. Furthermore, gastric cancer arising after vagotomy and pyloroplasty is more aggressive and occurs earlier than gastric cancer occurring after partial gastrectomy. ${ }^{4}$ Nicholls ${ }^{7}$ reported that carcinoma was more likely to arise following surgery for gastric ulcer than duodenal 
ulcer and this finding has recently been confirmed by Caygill et $a .^{2}$ In our patient the reduced acidity resulting from his HSV was compounded by the long term use of cimetidine. It has been postulated that treatment with cimetidine may result in the formation of potentially carcinogenic metabolites ${ }^{8}$ or intragastric $N$-nitrosamines, ${ }^{9}$ although a recent postmarketing surveillance $^{10}$ of patients taking cimetidine did not

\section{References}

1. Clark, C.G., Fresini, A. \& Gledhill, T. Cancer following gastric surgery. Br J Surg 1985, 72: 591-594.

2. Caygill, C.P.J., Hill, M.J., Kirkham, J.S. \& Northfield, T.C. Mortality from gastric cancer following gastric surgery for peptic ulcer. Lancet 1986, i: 929-931.

3. Stalsberg, H. \& Taksdal, S. Stomach cancer following gastric surgery for benign conditions. Lancet 1971, ii: $1175-1177$.

4. Totten, J., Burns, H.J.G. \& Watt Kay, A. Time of onset of carcinoma of the stomach following surgical treatment of duodenal ulcer. Surg Gynecol Obstet 1983, 157: 431-433.

5. Domellof, L., Reddy, B.S. \& Weisburger, J.H. Microflora and deconjugation of bile acids in alkaline reflux after partial gastrectomy. Am J Surg 1980, 140: 291-295.

6. Dewar, P., King, R. \& Johnston, D. Bile acid and lysolecithin concentrations in the stomach in patients with duodenal ulcer before operation and after treatment by highly selective vagotomy, partial gastrectomy or truncal vagotomy and drainage. Gut 1982, 23: 569-577.

7. Nicholls, J.C. Carcinoma of the stomach following par- show any excess deaths from gastric cancer. With an increasing trend towards the more 'physiological' $z$ operation of ulcer excision and highly selective $\unrhd$ vagotomy for the surgical treatment of gastric ulcers ${ }^{11,12} \subseteq$ we conclude that cimetidine should be used with $\vec{F}$ caution in these patients and that this operation may not be the appropriate choice for gastric ulcer.

tial gastrectomy for benign gastroduodenal lesions. $\mathrm{Br} \mathrm{J}$ Surg 1974, 61: 244-249.

8. Elder, J.B., Ganguli, P.C. \& Gillespie, I.E. Cimetidine and gastric cancer. Lancet 1979, i: 1005-1006.

9. Stockbrugger, R.W., Cotton, P.B., Eugenides, N., Bartholomew, B.A., Hill, M.J. \& Walters, C.L. Intragastric nitrites, nitrosamines and bacterial overgrowth during cimetidine treatment. Gut 1982, 23: 1048-1054.

10. Colin-Jones, D.G., Langman, M.J.S., Lawson, D.H. \& ज Vessey, M.P. Postmarketing surveillance of the safety of $\nexists$ cimetidine: mortality during second, third and fourth 윽 years of follow up. Br Med J 1985, 291: 1084-1088.

11. Johnston, D. Modern surgical attitudes to peptic ulceration. In Hadfield, J. \& Hobsley, M. (eds) Current Surgical Practice, vol. 1. Arnold, London, 1976, pp. 73-113.

12. Emas, S. \& Fernstrom, M. Prospective, randomized trial of selective vagotomy with pyloroplasty and selective proximal vagotomy with and without pyloroplasty in the treatment of duodenal, pyloric and prepyloric ulcers. $A$ m . J Surg 1985, 149: 236-243. 